\title{
QUALITY CONTROL FOR MICROBIOLOGICAL CULTURE MEDIA. IS IT ENOUGH TO FOLLOW THE NCCLS M22-A2 PROCEDURES?
}

\author{
Vlademir Vicente Cantarelli ${ }^{1,2 *}$; Everton Inamine ${ }^{1}$; Teresa Cristina Zenobin Brodt ${ }^{1}$; \\ Carina Secchi $^{1}$; Fabiana de Souza Pereira ${ }^{2}$; Maria Cristina Amaro ${ }^{1}$; Alice Aurora Batalha ${ }^{3}$; \\ Simone Dornellas Ligiero ${ }^{4}$
}

\begin{abstract}
Weinmann Laboratório Ltda., setores de ${ }^{1}$ Microbiologia e ${ }^{2}$ Biologia Molecular. bioMérieux Brasil S.A., ${ }^{3}$ Microbiologia e ${ }^{4}$ Divisão de Industria \& Meio Ambiente, Porto Alegre, RS, Brasil.
\end{abstract}

This paper corresponds to an "extended abstract" selected for oral presentation in the $22^{\text {nd }}$ Brazilian Congress of Microbiology, held in Florianópolis, SC, Brazil, in November 17-20, 2003

\begin{abstract}
Stringent quality control protocols must be used in order to guaranty that a particular medium is able to recover all sort of organism that may be present in clinical samples. Our aim was to evaluate an alternative protocol that would allow us to detect medium failure to yield quantitative growth of selected pathogens, and compare with the document M22-A2 from NCCLS. The detection limit of Haemophilus influenzae was significantly different depending on media source. We conclude that for some fastidious microorganisms, quantitative verification of the growth capacity of the culture medium is advised.
\end{abstract}

Key words: quality control, culture medium, NCCLS.

\section{INTRODUCTION}

Standard protocols specific for culture media have been developed by The National Committee for Clinical Laboratory Standards (NCCLS) and is known as document M22-A2 (3). Document M22-A2 recommend the microbiology laboratory to retest commercial media with a described failure rate of $\leq 0.3 \%$. Nevertheless, document M22-A2 does not describe procedures to evaluate the capacity of a given medium to recover a known amount of inoculated organisms, and whether or not the results are comparable, when different medium lots or sources are used.

The aim of this study was twofold: (i) to detect variation in the detection rate of a particular microorganism when testing several plates of the same lot, and (ii) to use the test to compare commercially prepared microbiological culture media with those prepared in-house, in order to validate media from different suppliers.

\section{MATERIALS AND METHODS}

The following strains were obtained from the American Type Culture Collection (ATCC) and were used in this study: Neisseria meningitidis (ATCC 13090), N. gonorrhoeae (43069), Streptococcus pneumoniae (6305), S. agalactiae (12386) and Haemophilus influenzae (10211). A bacterial suspension equivalent to that of a $3.0 \mathrm{McFarland}$ was prepared, and $50 \mu \mathrm{L}$ of this suspension was added to $9.0 \mu \mathrm{L}$ of sterile saline. Next, tenfold dilutions were prepared beginning with the working suspension, and $100 \mu \mathrm{L}$ of each dilution were used to inoculate the agar plates. The expected colony counts ranged from $4.5 \mathrm{x}$ $10^{4}$ to $<10 \mathrm{CFU} /$ plate. Each dilution was inoculated onto two commercial or two in-house plates. The experiment was repeated using four different lots from each medium source.

The agar plates used in this study were: sheep blood agar (SBA), chocolate agar (CA), and Thayer Martin medium (TM). Commercially available agar plates were obtained from a local

*Corresponding author. Mailing address: Rua Ramiro Barcelos, 910. 90035-001, Porto Alegre, RS, Brasil. Tel.: (+5551) 3314-3850. Fax: (+5551) 3311-7813. E-mail: vcantarelli@weinmann.com.br 
supplier (bioMérieux Brasil SA, RJ, Brazil). Plate media were also prepared in house using dehydrated powder media (Oxoid, UK) and other necessary supplements (Sheep blood, supplement VX and V.C.N - Laborclin, PR, Brasil), exactly as directed by the manufacturer.

After inoculation, both commercial and in-house plates were incubated under the same conditions following standard microbiology procedures (2), and the average number of colonies for each medium were recorded.

For comparison, agar plates from both sources, were also submitted to the validation test described in the NCCLS M22A2 document.

\section{RESULTS}

Results from SBA using S. pneumoniae and S. agalactiae, and TM with $N$. meningitidis or $N$. gonorrhoeae, showed no marked difference in terms of colony counting, irrespective of medium source.

Chocolate agar, on the other hand, showed a remarkable difference regarding the recovery of $H$. influenzae (Fig. 1). Inhouse plates displayed a limited capacity to recover this organism compared to the commercial plates. In fact, only 5 colonies could be obtained were the expected colony count was $4.5 \times 10^{3} \mathrm{CFU}$ (Fig. 2).

The CA plates were also tested using the procedures described in the NCCLS M22-A2 document, which uses a bacterial suspension known to provide 1 to $2 \times 10^{4} \mathrm{CFU} /$ plate, showing typical colonies, irrespective of its source. This result is in accordance with the result obtained with our test when $10^{4}$ CFU of $H$. influenzae were inoculated on both commercial and in-house chocolate agar plates, if only growth or non-growth would have been recorded.

\section{DISCUSSION}

The procedure described in the NCCLS M22-A2 document can be used to check for failure to support growth or yield the expected colony size. Our in-house media were all approved

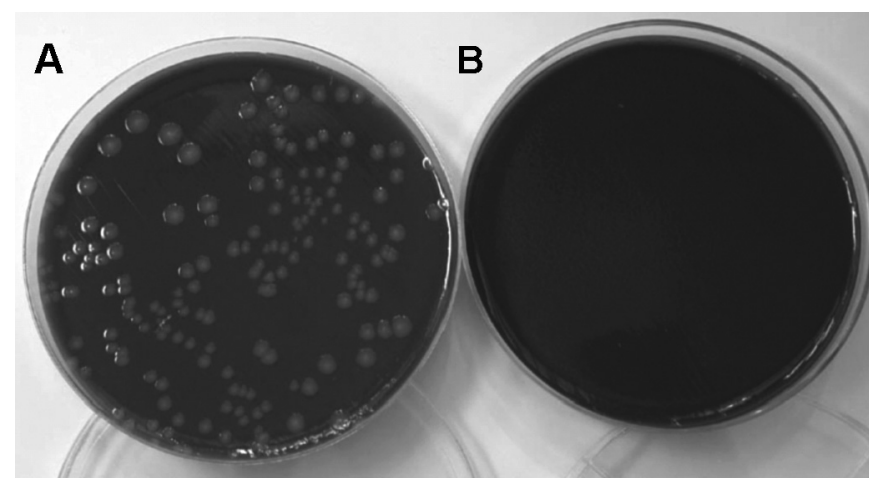

Figure 1. Recovery of Haemophilus influenzae H. influenzae containing was inoculated in both commercial (A) and homemade (B) chocolate agar.

following the M22-A2 guidelines. However, our results demonstrated that some media may have a limited capacity to recover fastidious microorganisms, such as $H$. influenzae, which is in accordance with previously published data (1).

Clinical microbiology laboratories may also use our protocol to validate culture media obtained from different suppliers. Only media which provide an equal or better recovery capacity should be validated and introduced in the lab's routine. By using such tests, laboratories may improve their capacity to isolate fastidious microorganisms.

In summary, we report here on the variability of the growth capacity of some media, particularly to isolate fastidious organisms like $H$. influenzae. Checking all media with several dilutions of two or more organisms may be unnecessary. We suggest that only those media used to recover fastidious pathogens, that may be present at very low concentration in a critical clinical sample, be tested using the protocol described here. For other less critical media, following the NCCLS M22-A2 guidelines may be adequate.

\section{ACKNOWLEDGMENTS}

We thank bioMeriéux Brasil S.A. for providing the necessary materials for the completion of this study.

Figure 2. Recovery of bacteria using commercial and in house agar plates. Results are the average counting from duplicated plates for each dilution. Recovery of $H$. influenzae was not satisfactory using home-made chocolate agar. Compare with the recovery of $N$. meningitidis using the same lots of chocolate agar plates.

\begin{tabular}{ccccccc}
\hline N. meningitidis & \multicolumn{2}{c}{ Colony count } & H. influenzae & & \multicolumn{2}{c}{ Colony count } \\
\cline { 2 - 3 } \cline { 5 - 6 } \# of CFU (Predicted) & Com $^{*}$ & In-house & \# of CFU (Predicted) & Com. ${ }^{*}$ & In house \\
\hline $4.5 \times 10^{4}$ & $>1000$ & $>1000$ & $4.5 \times 10^{4}$ & $>1000$ & 35 \\
$4.5 \times 10^{3}$ & $>1000$ & $>1000$ & $4.5 \times 10^{3}$ & $>100$ & 5 \\
$4.5 \times 10^{2}$ & $>100$ & $>100$ & $4.5 \times 10^{2}$ & 35 & 0 \\
$4.5 \times 10^{1}$ & 35 & 36 & $4.5 \times 10^{1}$ & 6 & 0 \\
$4.5 \times 10^{0}$ & 5 & 5 & $4.5 \times 10^{0}$ & 0 & 0 \\
\hline
\end{tabular}

$*$ Com $=$ commercial media. 


\section{RESUMO}

\section{Controle de qualidade de meios de cultura microbiológicas. Suficiente para atender os procedimentos NCCLS M22-A2?}

O uso de protocolos de controle de qualidade com padrões rígidos devem ser utilizados para garantir o isolamento dos microrganismos. Nosso objetivo foi o de avaliar um procedimento alternativo que nos permitisse detectar falhas de crescimento bacteriano em termos quantitativos, e comparação com o protocolo estabelecido pelo documento M22-A2 do NCCLS. Haemophilus influenzae apresentou diferença significativa de crescimento entre meio de cultivo de fontes distintas. Nos concluímos que, para alguns microrganismos fastidiosos, seja feita uma verificação quantitativa da capacidade de crescimento de cada meio de cultivo.

Palavras-chaves: controle de qualidade, meios de cultivo, NCCLS.

\section{REFERENCES}

1. Ciola, C.S.; Batalha, A.A.; Ligiéro, S.D.; Xavier, C.A. Por que os meios de cultura industrializados precisam ser validados antes de serem integrados à rotina laboratorial? Um estudo de caso. Cont. Contamin. 44:22-28, 2002.

2. Murray, R.P.; Baron, E.J.; Pfaller, M.A.; Tenover, F.C.; Yolken, R.H. (eds). Manual of Clinical Microbiology. American Society for Microbiology, Washington, D. C. 1999.

3. NCCLS. Quality Assurance for commercially Prepared Microbiological Culture Media - Approved standard. NCCLS M22-A2. Wayne, PA, USA. 